\title{
Designing sugar mimetics: Non-natural pyranosides as innovative chemical tools
}

Regis C. Saliba* and Nicola L. B. Pohl*

Department of Chemistry, Indiana University, Bloomington, IN 47401

The importance of oligosaccharides in myriad biological processes are becoming increasingly clear. However, these carbohydrate-mediated processes are often challenging to dissect due to the often poor affinity, stability and selectivity of the oligosaccharides involved. To circumvent these issues, non-natural carbohydrates-carbohydrate mimicsare being designed as innovative tools to modify biomolecules of interest or to understand biological pathways using fluorescence microscopy, $\mathrm{X}$-ray or nuclear magnetic resonance spectroscopy (NMR). This review focuses on key examples of recently developed nonnatural sugars to answer specific biological needs.

\begin{tabular}{|c|c|c|}
\hline & 1 & 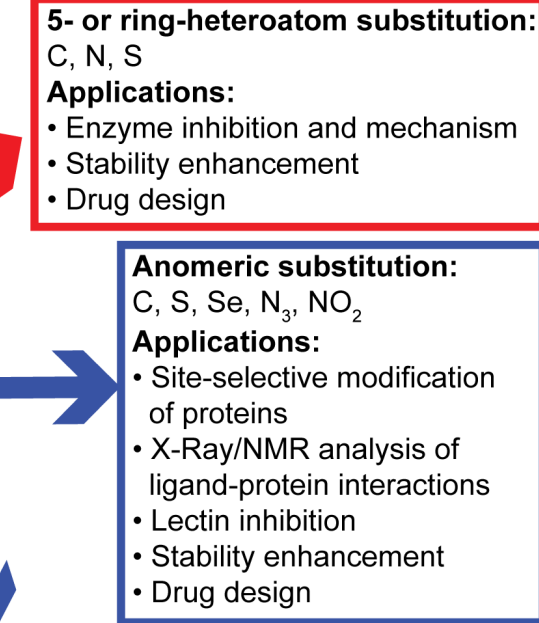 \\
\hline $\begin{array}{l}\text { 2,3,4,6-position } \\
\text { substitutions: } \\
\mathrm{F}, \mathrm{S}, \mathrm{NHCOR}^{-} \mathrm{N}_{3} \text {, } \\
\mathrm{CH}_{2} \mathrm{PO}_{3}^{2-}, \mathrm{CH}_{2} \mathrm{SO}_{3}^{-} \text {, } \\
\text { Photocage } \\
\text { Applications: } \\
\text { - In vivo bioimaging } \\
\text { - In vitro and in vivo } \\
\text { biodistribution and } \\
\text { expression of } \\
\text { oligosaccharides } \\
\text { - NMR studies of } \\
\text { protein-ligand interaction } \\
\text { - Enzyme mechanism } \\
\text { and inhibition } \\
\text { - Selective activation } \\
\text { - Stability enhancement }\end{array}$ & $\begin{array}{l}\text { Anomeric substitution in glycosidic } \\
\text { linkage: } \\
\text { C, S, Triazole }\end{array}$ & $\begin{array}{l}\text { Applications: } \\
\text { - Stability enhancement } \\
\text { - Study of carbohydrate conformation } \\
\text { - Quick assembly of polymeric structures }\end{array}$ \\
\hline
\end{tabular}


Glycans (oligo- or polysaccharides) are a class of compounds composed of monosaccharides - often 6-membered-ring pyranosides or 5-membered-ring furanosides-linked together by glycosidic bonds. Compared to the usually linear amino acid or oligonucleotide chains, glycans can adopt not only linear but also intricate branched structures. For example, the whole mammalian glycome contains only 10 monosaccharides (Glc, Gal, Man, Xyl, Fuc, Neu5Ac, GlcA, IdoA, GlcNAc, GalNAc), but these can form a huge variety of complex 3dimesional structures [1] that can be further elaborated with functionalities such as phosphates or sulphates [2]. Carbohydrates have become a major target of study to understand biological pathways and manipulate them for vaccine [3] and therapeutics development for oncology [4,5] and other disease states. However, glycans can be incredibly complex to synthesize or to obtain in pure form from natural sources and can also undergo unwanted degradation or modification by glycosidases and other enzymes. To overcome these drawbacks that have made the use of sugars difficult for biological studies and therapeutics development, scientists are actively designing non-natural oligosaccharide mimics (Figures 1 and 2) by substituting part of the glycan with other functional groups or molecular scaffolds in order to track the analog in vitro and/or in vivo, enhance its affinities and specificities towards selected targets, or increase its stability. Although non-natural furanosides such as ribose or deoxyribose mimics often found in nucleic acids and medicinal chemistry are beyond the scope of this article, the focus is on developments reported since 2012 in "non-natural" pyranoside-type sugars and their uses to solve biological problems. These challenges include the determination of enzyme-sugar interactions, the effects of protein glycosylation, the distribution in vivo and in vitro of glycocalyx, and the design of drugs and carriers. 


\section{Fluorine-modified sugars}

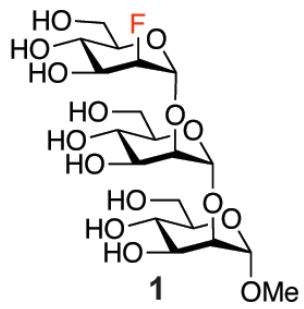

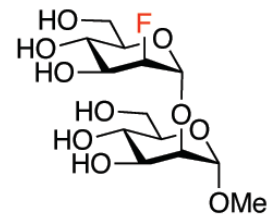

2

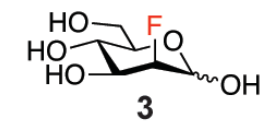

Determination of lectin affinity for specific anomer by STD-NMR

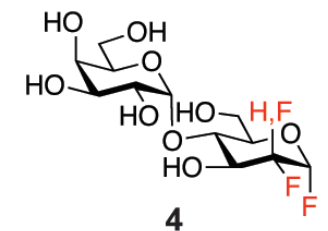

Covalent inhibitor for X-ray analysis of protein-ligand interaction

Size-dependent protein-ligand affinity by STD-NMR<smiles>O=C1POOPNC1Cc1cn(C2OCC3(O)COCC2(F)C3(F)F)nn1</smiles>

5

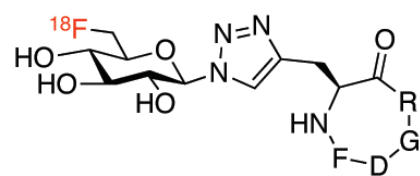

6

Biodistribution analysis by PET imaging

Seleno- and thio-modified sugars

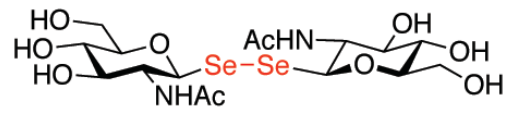

8

Protein-ligand affinity by ${ }^{77} \mathrm{Se}$ NMR

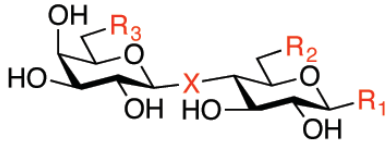

$10 \mathrm{X}=\mathrm{O}, \mathrm{R}_{1}=$ SeMe, $\mathrm{R}_{2}=\mathrm{R}_{3}=\mathrm{H}$

$11 X=O, R_{2}=$ SeMe, $R_{1}=R_{3}=H$

$12 X=O, R_{3}=$ SeMe, $R_{1}=R_{2}=H$

$13 X=S e, R_{1}=R_{2}=R_{3}=H$

Protein-ligand binding by SAD/MAD X-ray

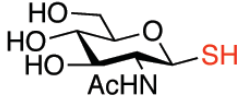

9

Site-selective modification of proteins to mimic protein glycosylation

Aminooxime-modified sugar

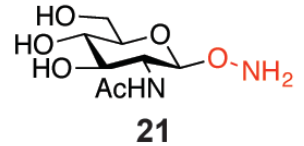

Glycosylation mimic to provide homogeneous glycosylated antibodies

Aziridine-modified sugars

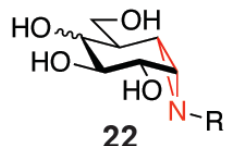

Covalent inhibitor

Phosphonate-modified sugar

$\mathrm{H}_{2} \mathrm{O}_{3} \mathrm{P}-\mathrm{CH}_{2} \mathrm{OH}$<smiles>CCC(C)CC(O)C1OC(O)(C(=O)O)CC(O)(C(=O)O)C1O</smiles>

23

Covalent enzyme inhibitor

to study new mode of binding

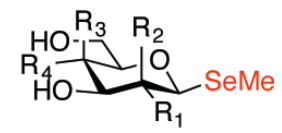

$14 \mathrm{R}_{1}=\mathrm{R}_{4}=\mathrm{OH}, \mathrm{R}_{2}=\mathrm{R}_{3}=\mathrm{H}$

$15 \mathrm{R}_{1}=\mathrm{R}_{3}=\mathrm{OH}, \mathrm{R}_{2}=\mathrm{R}_{4}=\mathrm{H}$

$16 \mathrm{R}_{2}=\mathrm{R}_{4}=\mathrm{OH}, \mathrm{R}_{1}=\mathrm{R}_{3}=\mathrm{H}$

$17 \mathrm{R}_{1}=\mathrm{NHAC}, \mathrm{R}_{4}=\mathrm{OH}, \mathrm{R}_{2}=\mathrm{R}_{3}=\mathrm{H}$

$18 \mathrm{R}_{1}=\mathrm{OH}, \mathrm{R}_{4}=\mathrm{Gal}, \mathrm{R}_{2}=\mathrm{R}_{3}=\mathrm{H}$

Protein-ligand affinity by ${ }^{77} \mathrm{Se}$ NMR

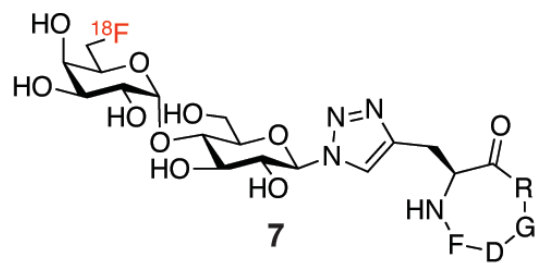

Photocaged sugars

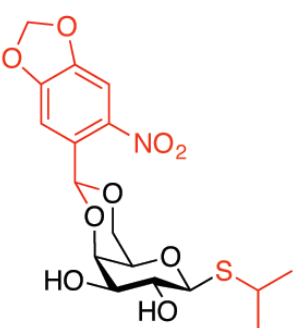

19

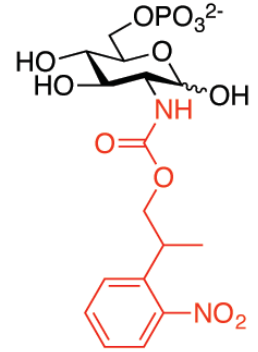

20
Temporal control of protein expression and gene regulation

\section{Triazole-linked sugars}

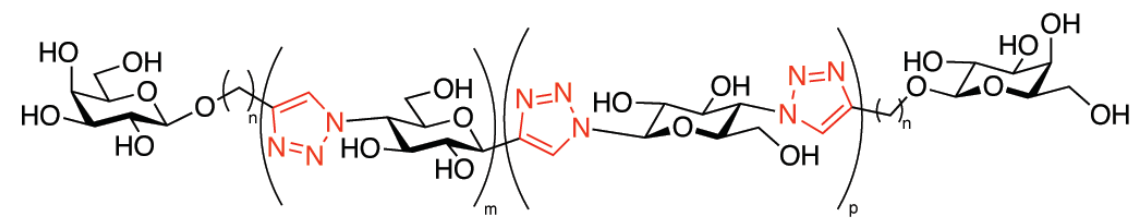

$24 \mathrm{n}=1, \mathrm{~m}=1, \mathrm{p}=1,25 \mathrm{n}=3, \mathrm{~m}=1, \mathrm{p}=1$

$26 n=1, m=1, p=2,27 n=3, m=1, p=2$

$28 n=1, m=2, p=2,29 n=3 . m=2, p=2$

Size-selective semi-rigid spacer for multivalent binding

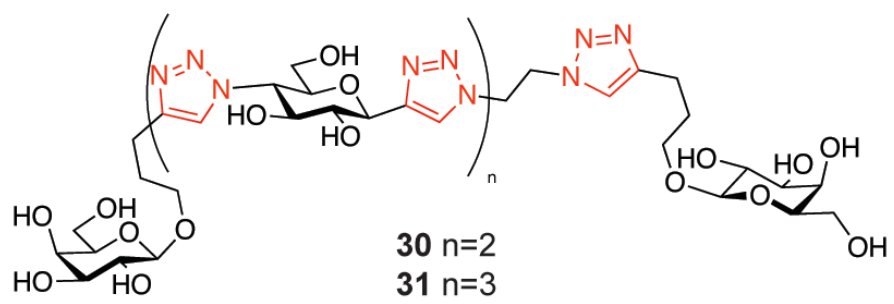

Size-selective semi-rigid spacer for multivalent binding

Figure 1. Non-natural sugars incorporate a variety of chemical modifications (highlighted in red) for specific applications (noted in blue). 


\section{Non-natural sugars to measure ligand-protein affinities}

The measurement of the affinity of cell surface oligosaccharides to their potential protein receptors is complicated by their often poor affinity in monovalent form towards the receptor protein. Oligosaccharides are a major component of the membranes of bacteria as well as plant, fungal, and mammalian cells and are important for cell-cell recognition and cell-pathogen recognition, often via the interaction of a specific glycan with a protein receptor. Fortunately, the development of saturation-transfer difference nuclear magnetic resonance spectroscopy (STDNMR) has helped circumvent some of the problems of studying these interactions at the molecular level. However, data from these types of experiments are very complex and thereby tedious to analyze, especially with mixtures of compounds such as the interconverting anomer mixtures of unconjugated sugars.

The introduction into an oligosaccharide of nuclear spin $1 / 2$ atoms such as naturally abundant fluorine-19 that are not present in the natural ligand or receptor can allow measurements of binding affinity by broadening and decrease of the NMR signal in STD-NMR experiments. Fluorine is rarely present in the solvent or the receptor and therefore is a particularly useful atom to introduce into a glycan mimic. For example, the selective affinity for the two binding sites of cyanovirin-N was probed with a tri- (1) and di-mannoside (2) in which the 2-position of the terminal mannoside was substituted with ${ }^{19} \mathrm{~F}$. Both oligosaccharides showed a shift in the fluorine spectra from the free form to that in complex with the A site or in complex with the B site and has allowed accurate determination of the binding mode of this oligosaccharide to the protein [6]. The introduction of ${ }^{19} \mathrm{~F}$ was also used in STD- ${ }^{19} \mathrm{~F}-\mathrm{NMR}$ experiments to demonstrate the higher affinity of the mannose-binding protein concanavalin A toward the $\alpha$-anomer of an anomeric mixture of 2-deoxy-2-fluoro-D-mannopyranosides (3). Interestingly, these experiments also allowed measurements of the binding constants of each distinct anomer of the mixture [7].

Selenium, specifically ${ }^{77} \mathrm{Se}$, is another nucleus that has been incorporated into sugar mimics for NMR and X-ray studies. Bis-( $\beta$-D-GlcNAc) (8) [8] diselenide and other selenomonosaccharides (14-18) [9] enabled facile carbohydrate-protein affinity measurements with lectins such as WPA, PNA and ConA. Selenosugars have even been detected in biofluids using ${ }^{77} \mathrm{Se}-\mathrm{NMR}[8]$. In addition to its $1 / 2$ spin, ${ }^{77}$ Se shows anomalous dispersion and thereby was used in X-ray crystallography resolution of protein-seleno-modified carbohydrate complexes (10-13) instead of using genetically modified proteins to incorporate ${ }^{77} \mathrm{Se}$. Single-wavelength anomalous diffraction/multi-wavelength anomalous dispersion (SAD/MAD) X-ray experiments allowed the determination of a high-resolution structure of the galectin- $9 \mathrm{~N}$-terminal CRD in complex with the 6-SeMe-Lac (11) [10].

\section{Non-natural sugars to understand ligand-protein interactions and enzymatic pathways}

In addition to use with NMR and X-ray techniques, sugar mimetics can also serve to probe protein/ligand interactions. Replacement of key hydroxyls of a natural sugar ligand with larger atoms and/or poorer H-bond donors such as thiol lead to a decrease of binding affinity. This approach, for example, demonstrated that the 4,6-positions of mannose are the most important for its binding with the plant lectin ConA [11]. 
Even transient intermediates not amenable to NMR or X-ray visualization can be probed with carefully designed sugar mimetics. For example, the mode of interaction between maltose GlcE, an enzyme involve in the synthesis of cytoplasmic $\alpha$-glucan notably found in M. tuberculosis, and its maltose ligand was probed with various fluorine modifications (4). An anomeric fluorine increases the rate of nucleophilic attack at the anomeric position by enzyme residue Asp394 to form a covalent bond between the protein and the oligosaccharide. Fluorines substituted at the second position, in addition to having higher $\mathrm{H}$-bond donor properties than the native $-\mathrm{OH}$, destabilize the formation of the oxocarbenium ion and thus the reaction of the substrate with the acceptor partner as well as the release of the intermediate. These modifications ultimately render the enzyme-substrate covalent bond enough stability for crystallization of the complex for X-ray analysis [12,13]. Similarly, use of the fluorinated glycoside at the 2-position was used for enzyme inhibition in vitro [14] and lectin in vivo [15]. For the same purpose-avoiding the formation of the key intermediate oxocarbenium ion - the inter ring heteroatom could be replaced with a carbon linked to the anomeric position via an aziridine ring (22). The resulting structural ring strain of the aziridine accelerates the formation of the covalent bond between the substrate and the receptor, whereas the substitution of the oxygen with the carbon avoids the formation of the reactive oxocarbenium intermediate. This strategy has been applied in vitro for the inhibition of $\beta$-glucosidases GBA, GBA2 and GBA3 [16] and with fluorescent aziridine for the inhibition of $\alpha$-galactosidase $A$ and $B$ [17] and potentially the monitoring of these enzymes in Fabry disease.

\section{Non-natural sugars to control and study biological pathways in vitro}

The problem of protein-linked glycan heterogeneity in the study of carbohydrate structure/function relationships has prompted the development of tools that allow the siteselective attachment of structurally well-defined sugars through modified anomeric positions to complementarily genetically-modified proteins of interest [18-21]. For example, genetic modification of the normally glycosylated asparagine in the Fc part of an IgG1 antibody to cysteine and its subsequent selective modification to formylglycine allowed site-specific attachment of an aminooxy-modified glucosamine (GlcNAc, 21). This glucosamine could then be elongated enzymatically by EndoS-D223Q using an oxazolidine-containing oligosaccharide to provide a homogenously glycosylated Fc [19]. Similarly, a $S$-GlcNAc (9) was site-selectively incorporated into a genetically-modified H2A-T101C histone, where a specific cysteine was converted to dihydroalanine. This modification enables mimicry of the natural tyrosine $O$ glycosylation and was used as a tool to demonstrate that the $O$-GlcNAcylation of T101 may be

responsible for disruption of the octamer formed by the histone couples $\mathrm{H} 2 \mathrm{~A} / \mathrm{B}$ with $\mathrm{H} 3 / \mathrm{H} 4$ and thus the destabilization of the nucleosome [21]. 


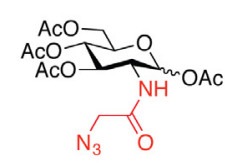

$\mathrm{Ac}_{4}$ GICNAz (32)

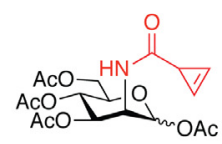

$\mathrm{Ac}_{4} \operatorname{ManNCp}(37)$
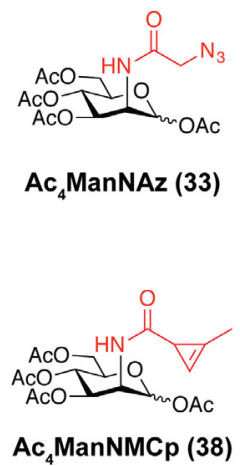

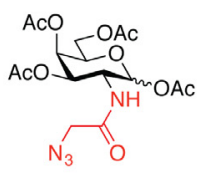

$\mathrm{Ac}_{4}$ GalNAz (34)

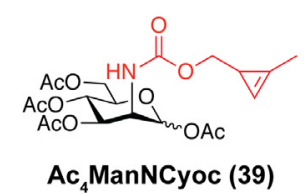

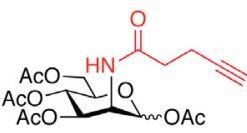

$\mathrm{Ac}_{4} \operatorname{ManNAI}(35)$

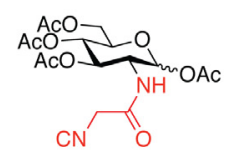

$\mathrm{Ac}_{4}$ GICN-n-Iso (36)

Figure 2. Examples of recent non-natural sugars used for metabolic incorporation that incorporate a motif for attachment of various tags via 'click' reactions.

In addition to serving as ways to make homogeneously glycosylated proteins, sugar mimics can also allow the investigation of natural cellular glycosylation patterns. To this end, several non-natural aminopyranosides in which the NHAc is replaced by readily reactive 'clickable' motifs, have been developed (Figure 3) [22-24]. These non-natural monosaccharides have been shown to be processed by the cell machinery to be incorporated at the cell surface either directly as GlcNAc or galactosamine (GalNAc) or after metabolization into mannosamine (ManNAc) mimics ManNAc to become sialic acid, Neu5Ac (Figure 3A). Once incorporated at the surface of the cells, the clickable motif of the sugar mimic can be uniquely reacted with a partner attached to a sensor molecule for analysis (Figure 3B). Some of these probes can even be reacted orthogonally to each other, thereby allowing the labelling of multiple modified glycans at once. For example, cyclopropene (37-39) [22,24] and iso-nitrile (36) [23] groups can be 'clicked' with a tetrazine motif in the presence of azido $(\mathrm{Az}, 32-34)$ groups that can selectively reacted with a cyclooctyl motif. This feature has been used to track single-molecule modified glycans (GalNAz or ManNAz) and measure their cell diffusion via total internal reflection fluorescence microscopy (TIRFM) by integrating a photo-bleaching step. Interestingly, this approach demonstrated the slower diffusion of sialylated glycans at the surface of cells with a high metastatic potential — cells that often have higher levels of sialylation — compared to cells with a low metastatic potential [25].

To further study glycosylation of a specific receptor, FRET experiments have been developed using azido-modified monosaccharides coupled to the FRET acceptor with FRET-donor-labelled proteins. With this system, a GLUT4 surface protein bearing an intracellular green fluorescent protein (GFP) FRET donor was expressed on genetically-modified HeLa cells. Cells were then incubated in the presence of $\mathrm{Ac}_{4} \mathrm{ManNAz}(\mathbf{3 3})$ and then 'clicked' with the FRET acceptor to create a FRET signal (Figure 3C-D). Further experiments using a N57Q-GLUT4 mutant lacking glycosylation sites showed that the FRET signal was not induced by any other transfer between the GFP. This setup was further used in looking at the dynamic process of cellular internalization of GLUT4 upon removal of insulin [26]. A 2-photon fluorescence lifetime FRET experiment was used to demonstrate the sialylation of the $\alpha_{v} \beta_{3}$ integrin expressed by the U87MG glioblastoma cell line. In this case, a Fab coupled to the FRET donor and specific for $\alpha_{\mathrm{v}} \beta_{3}$ was used instead of the genetically-modified receptor (Figure 3E), allowing direct imaging of the sialylation of the receptor in the U87MG cell model as well as in human prostate adenocarinoma tissues [27]. 


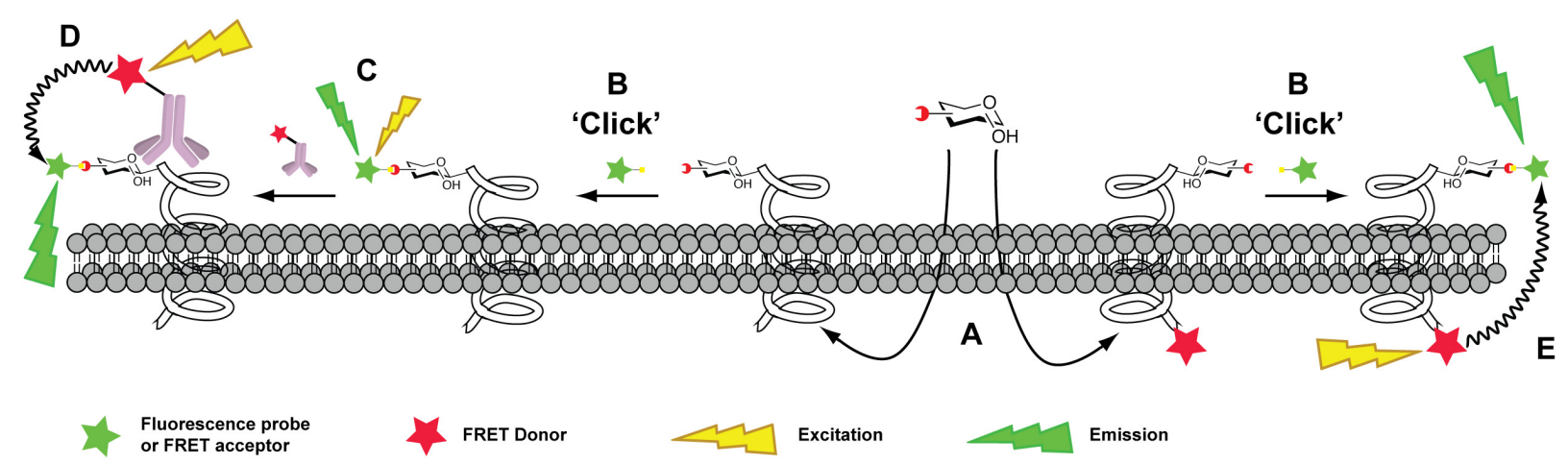

Figure 3. Application of non-natural sugar metabolic incorporation. Non-natural saccharides can be metabolically incorporated by cells at their surface (A) and then 'clicked' (usually by an azide-alkyne Huisgen cycloaddition) with a molecular label such as fluorescence probes (B). The probes can be used as a fluorescent marker for direct detection of glycosylation (C). Alternatively, the probes can be used as a FRET donor for determining specific protein glycosylation in the presence of a FRET acceptor that has been genetically incorporated into an antibody targeting the protein of interest (D) or directly to the protein of interest (E).

\section{Non-natural sugars for temporal control of cell machinery activation and in vivo imaging}

Oligosaccharides are often used by cells for the regulation of gene expression and protein expression. To allow gradual regulation and a more homogeneous induction of protein expression in a cell population [28], photocaged compounds have been developed for precise activation control of protein expression by irradiation [28-30]. For example, photocaged IPTG (19) was used successfully to homogeneously express YFP by a $\mathrm{LacY}^{-} / \mathrm{LacI}^{-}$bacterial E. coli Turner(DE3) [28]. Comparably, caged carbamate GlcN6P (20) was successfully used for the temporal activation of glmS responsible for the regulation of gene expression and thus the downregulation of EGFP in EGFP expressing HeLa cells [29].

Carbohydrates can also be easily modified to incorporate imaging tools. For instance, the ${ }^{18} \mathrm{~F}$ resulting positron emission tomography (PET) trace of modified RGB inhibitors (5-7) demonstrated their increased stability upon glycosylation by analysing its biodistribution in vivo [31]. Altered monosaccharides, such as a BCNSia (41), can also be injected directly in vivo in zebrafish embryos for cellular metabolism. After some development time, a fluorescent tetrazine probe designed to selectively react with the modified sialic acid was injected to ultimately create a map of the different sialylated structures present in the animal [32]. Likewise, the sugar nucleotide UDP-4-XylAz (40) was used in zebrafish to follow the incorporation of xylose at different stages of the development of the animal. The modified monosaccharide was also designed as a chain inhibitor of the glycosaminoglycan (GAG) synthesis to prove the importance of GAG in the normal development of the zebrafish. Further experiments, in the presence of a xylotransferase inhibitor, resulted in the decrease of incorporation of XylAz, thereby demonstrating the involvement of this transferase in the synthesis of GAG in zebrafish [33]. In related experiments, $\mathrm{Ac}_{4} \mathrm{GalNAz}$ (34) was used for incorporation in the glycosphingolipid chains predominantly present in mice in small cell lung cancer cells (LL2). Mice previously inoculated with LL2 cells were injected with the sugar probe. After days of incubation, the fluorescent twopart probe was injected sequentially. At the end of the final incubation, the tumor region showed a large fluorescence pattern compare to the negative control. However, kidney, small intestine, 
spleen and liver areas also showed large increases of fluorescence as seen in post mortem experiments due to the incorporation of GalNAz in these tissues [34].

\section{Non-natural sugars to enhance glycoside stability}

Glycosidic bonds are known to be easily hydrolyzed under mild acidic conditions or by glycosidase enzymes. Substitution of the glycosidic oxygen atom with sulfur [35-37] or carbon $[38,39]$ is a now common method to enhance stability of glycosides. Substitution of the pyranose oxygen, such as in 5-S glycosides, can possibly minimize structural changes [40] and such sugar mimics have shown increased cytotoxic activity towards cancer cell lines compared to their $O$ counterpart [41]. Similarly, substitution of the ring oxygen with carbon shows increased stability and lower clearance in vivo [42]. The substitution of an oxygen for a carbon can also be used to stabilized labile groups such as sulfate [43] and phosphate $[44,45]$ on sugar hydroxyls. In the phosphate case, the more stable phosphonate can be used specifically as an enzyme inhibitor [45] or can be be further substituted at the alpha-position for covalent inhibition [44]. In the former case, due to the non-labile properties of the phosphonate (23) compare to the phosphate, a new type of binding in the native reactive site of $N$-acetylneuraminate-9-phosphate phosphatase in complex with the ligand has been proposed using NMR [45].

\section{Non-natural sugars as linkers}

Carbohydrates also possess many properties that make them interesting for purposes beyond ligands. They are water soluble, can adopt defined rigid structures, can be readily functionalized on the hydroxyl moieties, and, with proper motif selection, can be recognized by the immune system as non-immunogenic or immunogenic, depending on the application. These properties have made sugar mimics interesting as linkers for ligand attachment. For example, multiple glucoses were linked together via a $\beta$-1,1 or a $\beta$-1,4 1,2,3-triazole linkage (24-31). The sugar moiety increased the hydrophilicity of the linker, whereas the triazole linkage formed via a 'click' reaction allowed quick assembly of the monosaccharide building blocks. In addition, the nature of the linkage renders the structure almost linear. This spacer was capped with two galactose monosaccharides and assayed against LecA as a multivalent chelate inhibitor. Interestingly, the size and the rigidity of the linker was important for optimum $\mathrm{IC}_{50}$ and could thereby be tuned for selectivity between different lectins [46-48].

The aforementioned metabolic labeling process with azide-modified sugars has also been used simply to readily introduce other functionalities, with the carbohydrate serving only as a unique linker. For example, the envelope of the measles virus was modified with an azido group by using metabolic incorporation of a non-natural glycoside from the host cell incubated in presence of $\mathrm{Ac}_{4} \mathrm{GalNAz}$ (34) or $\mathrm{Ac}_{4} \mathrm{ManNAz}$ (33). These modifications then allowed the introduction of fluorescent dyes and to provide a model for the development of potential virotherapeutic agents [49]. Multiple examples of modifications have also been applied to antibodies displaying low glycosylation heterogeneity. Sugar mimics thereby allow linkage of drugs of interest to generate antibody-drug conjugates (ADCs) with low drug/antibody dispersities. Moreover, as the carbohydrate region is far from the binding site of the ADC, the modification should not impact recognition of the antigen [50]. Similarly, a natural polysaccharides was selectively modified to 
'click' an immunogenic protein in a multivalent manner to produce a glyco-conjugate vaccine [51].

\section{Conclusion and perspective}

The recent design and use of non-natural sugars has enabled greater understanding of important biological pathways as well as the structural resolution of interaction modes between receptors or enzymes with their respective ligands. In addition, the importance of glycosylation in cell development and cell-cell interactions have been articulated with the in vivo and in vitro use of 'clickable' non-natural sugars, thereby serving as the basis for future work in the development of more potent and specific anticancer therapeutics or imaging reagents. However, to date, this work largely focuses only on small non-natural mono- and oligosaccharides. To extend the possibilities in the design of chemical biology probes, robust synthetic methods still need to be demonstrated for the facile production of non-natural mimics of larger glycans. Ideally, these new synthetic methods to link non-natural sugars to produce longer carbohydrate chains would all be developed with a view toward automation. Automated methods for oligosaccharide synthesis [52-57] show promise for the production of glycans, but so far this work is still focussed on the efficient production of natural oligosaccharides. If methods to make non-natural linkages or to incorporate non-natural sugars would be compatible with these automated methods to make natural oligosaccharides, more complex oligosaccharides could be readily built containing site-specific modifications in the glycan chain to control, for example, enzymatic degradation. For such compatibility with either solution- or solid-phase-based approaches, reactions would require reagents and solvents amenable to liquid-handling lines, avoid the production of solids, and demonstrate harmony with the protecting groups usually employed on these automation platforms. Such automated synthetic methods to string together or site-specifically incorporate sugars containing conformationally-locked sugar mimetics are also needed. The ability to freeze one of the ring conformations of a pyranoside could result in mimics with increased affinity and specificity for their targets as shown with the importance of L-IdoA in heparan sulphate in targeting the blood-coagulation factor $\mathrm{Xa}$ [43]. The work to design and synthesize more complex non-natural sugars has only just begun.

\section{Acknowledgements}

We would like to acknowledge the Joan and Marvin Carmack Chair, the U.S. National Institutes of Health (5U01GM1 16248-02 and HHSN272201400050C) and the US National Science Foundation (CHE-1362213) for their support of our own work in carbohydrates.

1. Werz DB, Ranzinger R, Herget S, Adibekian A, von der Lieth CW, Seeberger PH: Exploring the structural diversity of mammalian carbohydrates ("Glycospace") by statistical databank analysis. ACS Chem Biol 2007, 2:685-691.

\section{Zhang Y, Jiang H, Go EP, Desaire H: Distinguishing phosphorylation and sulfation in} carbohydrates and glycoproteins using ion-pairing and mass spectrometry. $J$ Am Soc Mass Spectr 2006, 17:1282-1288. 
3. Astronomo RD, Burton DR: Carbohydrate vaccines: developing sweet solutions to sticky situations? Nat Rev Drug Discov 2010, 9:308-324.

4. Fuster MM, Esko JD: The sweet and sour of cancer: Glycans as novel therapeutic targets. Nat Rev Cancer 2005, 5:526-542.

5. Hevey R, Ling CC: Recent advances in developing synthetic carbohydrate-based vaccines for cancer immunotherapies. Future Med Chem 2012, 4:545-584.

6. Matei E, Andre S, Glinschert A, Infantino AS, Oscarson S, Gabius HJ, Gronenborn AM: Fluorinated Carbohydrates as Lectin Ligands: Dissecting Glycan-Cyanovirin Interactions by Using F-19 NMR Spectroscopy. Chem Eur J 2013, 19:5364-5374.

7. Ribeiro JP, Diercks T, Jimenez-Barbero J, Andre S, Gabius HJ, Canada FJ: Fluorinated Carbohydrates as Lectin Ligands: 19F-Based Direct

STD Monitoring for Detection of Anomeric Selectivity. Biomolecules 2015, 5:3177-3192.

8. Perez-Victoria I, Boutureira O, Claridge TDW, Davis BG: Glycosyldiselenides as lectin ligands detectable by NMR in biofluids. Chem Coтmun 2015, 51:12208-12211.

9. Hamark C, Landstrom J, Widmalm G: SEAL by NMR: Glyco-Based Selenium-Labeled Affinity Ligands Detected by NMR Spectroscopy. Chem Eur J 2014, 20:13905-13908.

- 10. Suzuki T, Makyio H, Ando H, Komura N, Menjo M, Yamada Y, Imamura A, Ishida H, Wakatsuki S, Kato R, et al.: Expanded potential of seleno-carbohydrates as a molecular tool for X-ray structural determination of a carbohydrate-protein complex with single/multi-wavelength anomalous dispersion phasing. Bioorgan Med Chem 2014, 22:2090-2101.

Example of the use of ${ }^{77} \mathrm{Se}$ modified sugar in SAD/MAD ligand-protein x-ray analysis. By substituting the oxygen at different positions with the selenium, the authors show the limitation of this technique on the lack of protein-ligand binding.

11. Wu B, Ge JT, Ren B, Pei ZC, Dong H: Synthesis and binding affinity analysis of positional thiol analogs of mannopyranose for the elucidation of sulfur in different position. Tetrahedron 2015, 71:4023-4030.

-12. Syson K, Stevenson CEM, Rashid AM, Saalbach G, Tang MH, Tuukkanen A, Svergun DI, Withers SG, Lawson DM, Bornemann S: Structural Insight into How Streptomyces coelicolor Maltosyl Transferase GlgE Binds alpha-Maltose 1-Phosphate and Forms a Maltosyl-enzyme Intermediate. Biochemistry-Us 2014, 53:2494-2504.

Introduction of fluorine substitution of the hydroxyl at the 2- and anomeric position of maltose to covalently trap the intermediate formed between the M. tuberculosis GlcE and maltose allowed crystallization of the intermediate for X-ray analysis, an important step for the development of inhibitor of tuberculosis. 
13. Thanna S, Lindenberger JJ, Gaitonde VV, Ronning DR, Sucheck SJ: Synthesis of 2-deoxy2,2-difluoro- $\alpha$-maltosyl fluoride and its $X$-ray structure in complex with Streptomyces coelicolor GIgEI-V279S. Org Biomol Chem 2015, 13:7542-7550.

- 14. Wang L, Liu Y, Wu L, Sun X: Sialyltransferase inhibition and recent advances. Biochim Biophys Acta 2016, 1864:143-153.

Review of sialytransferase inhibitors including the use of fluorinated sialic acid derivatives.

15. Belcher JD, Chen CS, Nguyen J, Abdulla F, Nguyen P, Nguyen M, Okeley NM, Benjamin DR, Senter PD, Vercellotti GM: The Fucosylation Inhibitor, 2-Fluorofucose, Inhibits Vaso-Occlusion, Leukocyte-Endothelium Interactions and NF-kappa B Activation in Transgenic Sickle Mice. PLOS ONE 2015, 10.

16. Li KY, Jiang JB, Witte MD, Kallemeijn WW, Donker-Koopman WE, Boot RG, Aerts JMFG, Codee JDC, van der Marel GA, Overkleeft HS: Exploring functional cyclophellitol analogues as human retaining beta-glucosidase inhibitors. Org Biomol Chem 2014, 12:7786-7791.

17. Willems LI, Beenakker TJM, Murray B, Scheij S, Kallemeijn WW, Boot RG, Verhoek M, Donker-Koopman WE, Ferraz MJ, van Rijssel ER, et al.: Potent and Selective ActivityBased Probes for GH27 Human Retaining alpha-Galactosidases. $J$ Am Chem Soc 2014, 136:11622-11625.

18. Machida T, Lang K, Xue L, Chin JW, Winssinger N: Site-Specific Glycoconjugation of Protein via Bioorthogonal Tetrazine Cycloaddition with a Genetically Encoded trans-Cyclooctene or Bicyclononyne. Bioconjugate Chem 2015, 26:802-806.

19. Smith EL, Giddens JP, Iavarone AT, Godula K, Wang LX, Bertozzi CR: Chemoenzymatic Fc Glycosylation via Engineered Aldehyde Tags. Bioconjugate Chem 2014, 25:788795.

20. Boutureira O, Bernardes GJL, Fernandez-Gonzalez M, Anthony DC, Davis BG:

Selenenylsulfide-Linked Homogeneous Glycopeptides and Glycoproteins: Synthesis of Human "Hepatic Se Metabolite A". Angew Chem Int Edit 2012, 51:1432-1436.

•• 21. Lercher L, Raj R, Patel NA, Price J, Mohammed S, Robinson CV, Schofield CJ, Davis BG: Generation of a synthetic GlcNAcylated nucleosome reveals regulation of stability by H2A-Thr101 GlcNAcylation. Nat Commun 2015, 6.

Use of 1-thio- $N$-acetylglucosamine to site-selectively modify the T101C mutant of H2A to mimic the post-translational glycosylation of $\mathrm{H} 2 \mathrm{~A}$. The results demonstrate the role of glycosylation in the destabilization of the octamer formed between $\mathrm{H} 2 \mathrm{~A} / \mathrm{B}$ and $\mathrm{H} 3 / \mathrm{H} 4$ and thus the destabilization of the nucleosome.

22. Spate AK, Basskamp H, Niederwieser A, Schart VF, Marx A, Wittmann V: Rapid Labeling of Metabolically Engineered Cell-Surface Glycoconjugates with a CarbamateLinked Cyclopropene Reporter. Bioconjugate Chem 2014, 25:147-154. 
23. Wainman YA, Neves AA, Stairs S, Stockmann H, Ireland-Zecchini H, Brindle KM, Leeper FJ: Dual-sugar imaging using isonitrile and azido-based click chemistries. Org Biomol Chem 2013, 11:7297-7300.

24. Xiong DC, Zhu JJ, Han MJ, Luo HX, Wang C, Yu Y, Ye YQ, Tai GH, Ye XS: Rapid probing of sialylated glycoproteins in vitro and in vivo via metabolic oligosaccharide engineering of a minimal cyclopropene reporter. Org Biomol Chem 2015, 13:39113917.

•• 25. Jiang H, English BP, Hazan RB, Wu P, Ovryn B: Tracking Surface Glycans on Live Cancer Cells with Single-Molecule Sensitivity. Angew Chem Int Edit 2015, 54:17651769.

Metabolic incorporation of $\mathrm{Ac}_{4} \mathrm{ManNAl}$ and $\mathrm{Ac}_{4} \mathrm{GalNAz}$ to provide labelling of glycan at the cell surface. This feature, with the use of super-resolution and stochastic optical reconstruction microscopy, allows molecule tracking at the surface of the cell and determination of the mobility of glycans by analysis of their trajectories over-time. The results demonstrate that glycans diffuse more slowly in cells with high metastatic potential.

26. Haga Y, Ishii K, Hibino K, Sako Y, Ito Y, Taniguchi N, Suzuki T: Visualizing specific protein glycoforms by transmembrane fluorescence resonance energy transfer. Nat Commun 2012, 3.

27. Belardi B, de la Zerda A, Spiciarich DR, Maund SL, Peehl DM, Bertozzi CR: Imaging the Glycosylation State of Cell Surface Glycoproteins by Two-Photon Fluorescence Lifetime Imaging Microscopy. Angew Chem Int Edit 2013, 52:14045-14049.

- 28. Binder D, Grunberger A, Loeschcke A, Probst C, Bier C, Pietruszka J, Wiechert W, Kohlheyer D, Jaeger KE, Drepper T: Light-responsive control of bacterial gene expression: precise triggering of the lac promoter activity using photocaged IPTG. Integr Biol-Uk 2014, 6:755-765.

This study uses a photocaged IPTG for precise and gradual temporal induction of YFP in YFP expressing $\mathrm{LacY}^{-} / \mathrm{LacI}^{-}$E. coli Tuner(DE3) bacterial strain.

29. Wulffen B, Buff MCR, Pofahl M, Mayer G, Heckel A: Caged glucosamine-6-phosphate for the light-control of riboswitch activity. Photoch Photobio Sci 2012, 11:489-492.

30. Brieke C, Rohrbach F, Gottschalk A, Mayer G, Heckel A: Light-Controlled Tools. Angew Chem Int Edit 2012, 51:8446-8476.

31. Maschauer S, Haubner R, Kuwert T, Prante O: F-18-Glyco-RGD Peptides for PET Imaging of Integrin Expression: Efficient Radiosynthesis by Click Chemistry and Modulation of Biodistribution by Glycosylation. Mol Pharmaceut 2014, 11:505-515. 
- 32. Agarwal P, Beahm BJ, Shieh P, Bertozzi CR: Systemic Fluorescence Imaging of Zebrafish Glycans with Bioorthogonal Chemistry. Angew Chem Int Edit 2015, 54:11504-11510.

This study uses a bicyclononyne-functionalized sialic acid in live zebrafish embryos as a model to image sialylated glycoconjugates in vivo.

•• 33. Beahm BJ, Dehnert KW, Derr NL, Kuhn J, Eberhart JK, Spillmann D, Amacher SL, Bertozzi CR: A Visualizable Chain-Terminating Inhibitor of Glycosaminoglycan Biosynthesis in Developing Zebrafish. Angew Chem Int Edit 2014, 53:3347-3352. 4-Azido-4-deoxyxylose was used in live embryon of zebrafish as an inhibitor of the glycosaminoglycan (GAG) chain. The azido motif was 'clicked' to a probe to image the sites of inhibition in vivo. The decrease of fluorescence after co-incubation with a XylT1 inhibitor demonstrates the importance of the enzyme in GAG biosynthesis. The work shows the utility of non-natural sugar probes to study the role of GAG in animal development and successfully demonstrates the importance of GAG in the development of normal zebrafish embryos.

34. Neves AA, Stockmann H, Wainman YA, Kuo JCH, Fawcett S, Leeper FJ, Brindle KM: Imaging Cell Surface Glycosylation in Vivo Using "Double Click" Chemistry. Bioconjugate Chem 2013, 24:934-941.

35. Bi JJ, Zhao CF, Cui W, Zhang CL, Shan QL, Du YG: Synthesis and affinities of C3symmetric thioglycoside-containing trimannosides. Carbohydr Res 2015, 412:56-65.

36. Csavas M, Demeter T, Herczeg M, Timari I, Kover KE, Herczegh P, Borbas A: Rapid synthesis of self-assembling 1,2-thiomannobioside glycoconjugates as potential multivalent ligands of mannose-binding lectins. Tetrahedron Lett 2014, 55:6983-6986.

37. Adak AK, Yu CC, Liang CF, Lin CC: Synthesis of sialic acid-containing saccharides. Curr Opin Chem Biol 2013, 17:1030-1038.

38. Liu L, Motaal BA, Schmidt-Supprian M, Pohl NLB: Multigram Synthesis of Isobutyl-betaC-galactoside as a Substitute of Isopropylthiogalactoside for Exogenous Gene Induction in Mammalian Cells. J Org Chem 2012, 77:1539-1546.

39. Awad L, Madani R, Gillig A, Kolympadi M, Philgren M, Muhs A, Gerard C, Vogel P: A CLinked Disaccharide Analogue of Thomsen-Friedenreich Epitope Induces a Strong Immune Response in Mice. Chem Eur J 2012, 18:8578-8582.

40. Bi JJ, Wang J, Zhou K, Wang YC, Fang M, Du YG: Synthesis and Biological Activities of 5-Thio-alpha-GalCers. Acs Med Chem Lett 2015, 6:476-480.

41. Witczak ZJ, Poplawski T, Czubatka A, Sarnik J, Tokarz P, VanWert AL, Bielski R: A potential CARB-pharmacophore for antineoplastic activity: Part 1. Bioorg Med Chem Lett 2014, 24:1752-1757. 
42. Gao Q, Zaccaria C, Tontini M, Poletti L, Costantino P, Lay L: Synthesis and preliminary biological evaluation of carba analogues from Neisseria meningitidis A capsular polysaccharide. Org Biomol Chem 2012, 10:6673-6681.

43. Herczeg M, Lazar L, Bereczky Z, Kover KE, Timari I, Kappelmayer J, Liptak A, Antus S, Borbas A: Synthesis and Anticoagulant Activity of Bioisosteric Sulfonic-Acid Analogues of the Antithrombin-Binding Pentasaccharide Domain of Heparin. Chem Eur J 2012, 18:10643-10652.

44. Downey AM, Cairo CW: alpha-Bromophosphonate analogs of glucose-6-phosphate are inhibitors of glucose-6-phosphatase. Carbohydr Res 2013, 381:123-132.

45. Kim SH, Constantine KL, Duke GJ, Goldfarb V, Hunt JT, Johnson S, Kish K, Klei HE, McDonnell PA, Metzler WJ, et al.: Design, synthesis, functional and structural characterization of an inhibitor of $\mathrm{N}$-acetylneuraminate-9-phosphate phosphatase: Observation of extensive dynamics in an enzyme/inhibitor complex. Bioorg Med Chem Lett 2013, 23:4107-4111.

46. Pertici F, de Mol NJ, Kemmink J, Pieters RJ: Optimizing Divalent Inhibitors of Pseudomonas aeruginosa Lectin LecA by Using A Rigid Spacer. Chem Eur J 2013, 19:16923-16927.

47. Pertici F, Pieters RJ: Potent divalent inhibitors with rigid glucose click spacers for Pseudomonas aeruginosa lectin LecA. Chem Commun 2012, 48:4008-4010.

48. Visini R, Jin X, Bergmann M, Michaud G, Pertici F, Fu O, Pukin A, Branson TR, ThiesWeesie DME, Kemmink J, et al.: Structural Insight into Multivalent Galactoside Binding to Pseudomonas aeruginosa Lectin LecA. ACS Chem Biol 2015, 10:24552462.

- 49. Zhao X, Cai L, Adogla EA, Guan H, Lin Y, Wang Q: Labeling of Enveloped Virus via Metabolic Incorporation of Azido. Bioconjugate Chem 2015, 26:1868-1872.

Use of virus-infected cells to introduce at the surface of the virus, via the cell metabolism, nonnatural carbohydrate-bearing anchor portions that could be used to chemically modify the virus.

-50. Agarwal P, Bertozzi CR: Site-Specific Antibody-Drug Conjugates: The Nexus of Biciorthogonal Chemistry, Protein Engineering, and Drug Development. Bioconjugate Chem 2015, 26:176-192.

Review on antibody-drug conjugates including a section on the use of non-natural carbohydrates to attach drugs at the site of glycosylation on the $\mathrm{Fc}$ portion of the antibody.

51. Nilo A, Morelli L, Passalacqua I, Brogioni B, Allan M, Carboni F, Pezzicoli A, Zerbini F, Maione D, Fabbrini M, et al.: Anti-Group B Streptococcus Glycan-Conjugate Vaccines Using Pilus Protein GBS80 As Carrier and Antigen: Comparing Lysine and Tyrosine-directed Conjugation. ACS Chem Biol 2015, 10:1737-1746. 
52. Tang SL, Pohl NLB: Automated Solution-Phase Synthesis of beta-1,4-Mannuronate and beta-1,4-Mannan. Org Lett 2015, 17:2642-2645.

53. Hahm HS, Liang CF, Lai CH, Fair RJ, Schuhmacher F, Seeberger PH: Automated Glycan Assembly of Complex Oligosaccharides Related to Blood Group Determinants. $J$ Org Chem 2016, 81:5866-5877.

54. Komba S, Terauchi T, Machida S: Automated Synthesis of a Tri-branched Pentasaccharide: the Application of the Uni-chemo Hydroxyl Protection Method to the Automated Synthesis of Oligosaccharides. J. Appl. Glycosci. 2009, 56:193-206.

55. Nokami T, Hayashi R, Saigusa Y, Shimizu A, Liu CY, Mong KKT, Yoshida J: Automated Solution-Phase Synthesis of Oligosaccharides via Iterative Electrochemical Assembly of Thioglycosides. Org Lett 2013, 15:4520-4523.

56. Bauer J, Brandenburg K, Zahringer U, Rademann J: Chemical synthesis of a glycolipid library by a solid-phase strategy allows elucidation of the structural specificity of immunostimulation by rhamnolipids. Chem Eur J 2006, 12:7116-7124.

57. Ganesh NV, Fujikawa K, Tan YH, Stine KJ, Demchenko AV: HPLC-Assisted Automated Oligosaccharide Synthesis. Org Lett 2012, 14:3036-3039. 